\title{
Algorithm for comorbidities, associations, length of stay and mortality (ACALM)
}

\author{
Rahul Potluri*,1 \\ ${ }^{1}$ ACALM Study Unit in collaboration with Aston Medical School, Aston University, Birmingham, B4 7ET, UK \\ *Author for correspondence: rahulpotluri@outlook.com
}

\begin{abstract}
"The dream is personalized medicine and the ability to create a mechanism whereby using the data in big data groups such as ACALM, patients can be evaluated according to their characteristics and with a high degree of certainty, we can deliver patient-specific diagnostic and management options for their needs holistically."
\end{abstract}

First draft submitted: 23 May 2018; Accepted for publication: 5 June 2018; Published online: 18 July 2018

\section{Keywords: ACALM • big data $\bullet$ cancer $\bullet$ digital $\bullet$ future $\bullet$ hyperlipidemia $\bullet$ medicine $\bullet$ personalized $\bullet$ prospects $\bullet$} research • review

Over the past few decades, the concept of evidence-based medicine has developed with randomized controlled trials taking over as the gold standard underpinning clinical guidelines that are closely followed by doctors today [1-5]. In parallel, over the last 20 years, the growth of computerization has rapidly transformed healthcare in developed countries [6-10]. We now live in a medical environment where details of patients' histories, outcomes have been recorded for a variety of purposes ranging from hospital payments, physician billing, monitoring, insurance and in some cases for research purposes [11-13]. The value of the multidimensional information recorded was and is still unknown and therefore underutilized. Medicine is entering a new era - a digital era - where personalized medicine will be the norm using insights from such data [14,15].

Only a decade ago, data had to be collected and analyzed, often not in quantities large enough to show something that has not been done before. One needed grants, pharmaceutical funding etc., to run clinically impacting randomized trials and/or the status of a professor to run clinically relevant registries.

These challenges bore the idea of utilizing data which had been collected for other purposes rather than collecting data specifically for every project which is practically onerous. The compilation of the first algorithm for comorbidities, associations, length of stay and mortality (ACALM) dataset took almost 2 years of painful manual coding using a range of skills in IT and other self-taught skills but resulted in a dataset of 250,000 patients. A quarter of a million patients for medical research in 2007 was almost unheard of. We quickly went to work to utilize the research dataset by looking at diabetes, Alzheimer's disease, dementia and other psychiatric conditions [16-21].

All our research holds the same amalgamation code underpinning everything. Talking of coding, the process took 2 years the first time, 2 months when further hospitals collaborated, 2 weeks subsequently and now approximately 2 days.

ACALM actively explored associations including the suggested associated pathophysiology between breast cancer and cholesterol in mice [22]. A conclusive association in humans was not present at that time and utilizing ACALM, we found a significant association between high cholesterol and breast cancer in 664,000 women [23]. There was widespread media interest in this work including, a report in the TIME magazine postulating potential treatment strategies to tackle this association, including statins [24]. This was a turning point for ACALM because overnight we became internationally known. In 2016, we extended this research and showed that high-cholesterol patients in the four most common cancers in the UK, namely breast, prostate, colorectal and lung had significantly improved long-term mortality pointing to further investigation of the potential role of lipid lowering therapies, such as statins in their management $[25,26]$.

Subsequently, ACALM development became easier and collaborations happened at a faster rate including finding acceptability among the medical and scientific community regarding the methodology. Big data in my view is the 
concept of amalgamation of available data for a variety of purposes as opposed to collection of data for a specific purpose $[16,27]$. Second, the analysis of the available data using a variety of strategies including machine learning could lead to findings that are not possible to think of otherwise. Traditionally in medicine, we always tried to answer a preset hypothesis with a carefully designed study. Now we generate hypotheses from the results of big data analyses, and in future I am sure, we will in real time be able to integrate research and clinical practice into one seamless entity with advanced technology $[16,27]$. One of the main areas where this would be particularly helpful is in the fields of cancer and cardiovascular disease which combined contribute to the majority of deaths in the developed world $[27,28]$.

When 67-year-old patient A walks through the hospital door with hypertension, diabetes, high cholesterol, strong family history of breast cancer and dyspnoea with a 2-month history of weight loss, what is their diagnosis, what is their treatment, how will they do and how can we optimize their quality of life and avoid unnecessary hospital admission? Comparing characteristics of patient A with millions of patients before and their outcomes using real-time machine learning algorithms and treatment has the potential to answer a lot of the above questions while also adding one more patient to the database for increased accuracy which can be used when patient B walks through the door. Adding more points of data such as laboratory tests, imaging and other profiling factors such as weight/height/demographic, for example, would lead to increased granularity which will allow for better prediction. The technology is already available, we see evidence of it every day when we undertake a Google search and find advertisements related to our search and in the media we have recently seen examples of the potential for harm from this type of technology as the Cambridge Analytica data scandal [29].

The ACALM algorithm has now been expanded to not only evaluate information cross-sectionally but also to follow patient journeys through longitudinally which gives us the ability to develop disease and patient group specific risk scores on a scale not seen previously. In the UK, our studies have highlighted the 'weekend effect' - a phenomenon where patients admitted to hospitals outside of normal working hours and at weekends have worse long-term outcomes in spite of adjustment across a number of conditions such as acute coronary syndrome, heart failure, atrial fibrillation [30-34]. We were also the first to show the role of weekend discharge from hospital having a significant impact on long-term mortality in a 1 million patients over 14 years [30-34]. We are currently undertaking research looking the impact of weekend effect in individual conditions and particularly in cancer, access to imaging and related conditions such as palliative and supportive care. We have shown that marital status has a significant impact on long-term outcomes in patients with cardiovascular events such as acute coronary syndrome as well as risk factors such as hypertension, diabetes and hyperlipidemia [35,36]. I think our finding showing that married patients having better outcomes is a proxy for psychosocial support mechanisms present in relationships manifesting as improved outcomes. In fact, the impact of mental health on physical health is something we have investigated thoroughly, showing that mental health cannot be taken lightly and clearly more needs to be done [37-39]. More research is required evaluating mental health and psychosocial issues in patients with cancer and we are actively working on this at the moment. Our long-term aim is to evaluate the combined impact of cancer and cardiovascular disease [28]. I am convinced that the two biggest killers in the developed world interact with each other in ways we do not know and there are many more findings like the association between breast cancer and cholesterol that ACALM and big data research can uncover in due course.

The dream is personalized medicine and the ability to create a mechanism whereby using the data in big data groups such as ACALM, patients can be evaluated according to their characteristics and with a high degree of certainty, we can deliver patient-specific diagnostic and management options for their needs holistically. In order to get there, ACALM needs to grow much bigger with multiple facets and harness technology from Silicon Valley giants and perhaps collaborate with other big data networks.

\section{Financial \& competing interests disclosure}

The author has no relevant affiliations or financial involvement with any organization or entity with a financial interest in or financial conflict with the subject matter or materials discussed in the manuscript. This includes employment, consultancies, honoraria, stock ownership or options, expert testimony, grants or patents received or pending, or royalties.

No writing assistance was utilized in the production of this manuscript.

\section{References}

1. Keevil GM. The Roentgen rays. Br. Med. J. 1(1833), 433-434 (1896).

2. Fleming A. Penicillin: the Robert Campbell oration. Ulster Med. J. 13(2), 95-122 (1944). 
3. Watson JD, Crick FH. The structure of DNA. Cold Spring Harb. Symp. Quant. Biol. 18, 123-231 (1953).

4. Grüntzig A, Schneider HJ. The percutaneous dilatation of chronic coronary stenoses-experiments and morphology. Schweiz Med. Wochenschr. 107(44), 1588 (1977).

5. Smith J. Chloroform and anaesthesia. Br. Med. J. 2(782), 777-778 (1875).

6. Modell W, Garrett M. Interactions between pharmacodynamic and placebo effects in drug evaluations in man. Nature 185(4712), 538-539 (1960).

7. Chilton NW, Barbano JP. Guidelines for reporting clinical trials. J. Periodontal Res. Suppl. 14, 207-208 (1974).

8. Mahony C. What is NICE. National Institute for Clinical Excellence. Nurs. Times 95(10), 16 (1999).

9. Bigby M. Evidence-based medicine in a nutshell: a guide to finding and using the best evidence in caring for patients. Arch. Dermatol. 134(12), 1609-1618 (1989).

10. Dickersin K, Manheimer E. The Cochrane collaboration: evaluation of healthcare and services using systematic reviews of the results of randomized controlled trials. Clin. Obstet. Gynecol. 41(2), 315-331 (1998).

11. Spencer WA, Vallbona C. Application of computers in clinical practice. JAMA 191, 917-921 (1965).

12. Lowenstein E. The marriage of medicine and computers. Physician Exec. 19(6), 47, 50-53 (1993).

13. Robinson AT. Computerization of a patient record index. Natl Hosp. Health Care 1(12), $15-17$ (1976).

14. Coile RC Jr. The digital transformation of health care. Physician Exec. 26(1), 8-15 (2000).

15. Delrose DC, Steinberg RW. The clinical significance of the digital patient record. J. Am. Dent. Assoc. 131(Suppl.), 57S-60S (2000).

16. Potluri R, Drozdov I, Carter PR et al. Big data and cardiology: time for mass analytics. Eur. Med. J. 1(2), 15-17 (2016).

17. Potluri R, Natalwala A, Uppal H et al. Cardiovascular risk factors in vascular dementia and ischaemic stroke. Neuroepidemiology 31(1), 67-68 (2008)

18. Natalwala A, Potluri R, Uppal H et al. Reasons for hospital admissions in dementia patients in Birmingham, UK during $2002-2007$. Dement. Geriatr. Cogn. Disord. 26(6), 499-505 (2008).

19. Potluri R, Natalwala A. Increasing prevalence of haemorrhagic stroke among South Asian patients in the United Kingdom from 1997 to 2005. J. Clin. Neurosci. 16(4), 605-606 (2009).

20. Dowlut MS, Natalwala A, Uppal H et al. Secular trends in ovarian cancer admissions to a large general hospital during the period 2000-2007. Eur. J. Gynaecol. Oncol. 30(5), 562 (2009).

21. Potluri R, Natalwala A, Uppal H et al. Different risk factors in vascular dementia and ischaemic stroke. Neuroepidemiology $32(1)$, 80 (2009).

22. Nelson ER, Wardell SE, Jasper JS et al. 27-Hydroxycholesterol links hypercholesterolemia and breast cancer pathophysiology. Science 342(6162), 1094-1098 (2013).

23. Potluri R, Lavu D, Uppal H et al. Hyperlipidaemia as a risk factor for breast cancer. Cardiovasc. Res. 103(Suppl. 1), 135 (2014).

24. Park A. Why statins could be the next treatment for breast cancer. Time, 5 th July (2018). http://time.com/2954609/statins-breast-cancer/

25. Carter PR, McGowan J, Uppal H et al. Hyperlipidaemia reduces mortality in breast, prostate, lung and bowel cancer. Heart 102, A57-A58 (2016).

26. Potluri R, Carter PR, Lavu D, Bainey KR. The interplay between cholesterol and breast cancer: is there a potential role for statin therapy? Future Oncol. 14(19), 1885-1888 (2018).

27. Potluri R. Big data analytics for population analysis. European Society of Cardiology Conference. Rome 2016. (2018). https://congress365.escardio.org/Presentation/130893\#.Wux6AC7wbX4

28. Zamorano JL, Lancellotti P, Rodriguez Muñoz D et al. ESC Scientific Document Group. 2016 ESC position paper on cancer treatments and cardiovascular toxicity developed under the auspices of the ESC Committee for practice guidelines: the task force for cancer treatments and cardiovascular toxicity of the European Society of Cardiology (ESC). Eur. Heart J. 37(36), 2768-2801 (2016).

29. Solon O, Graham-Harrison E. The six weeks that brought Cambridge analytica down. The Guardian, 3rd May (2018). www.theguardian.com/uk-news/2018/may/03/cambridge-analytica-closing-what-happened-trump-brexit

30. Mathew A, Fyyaz SA, Carter PR et al. The enigma of the weekend effect. J. Thorac. Dis. 10(1), 102-105 (2018).

31. Potluri R, Chandran S, Uppal H. Out-of-hour and weekend admission to hospital with acute coronary syndrome confers poorer mortality and longer length of hospital stay. Heart 101, A1-A2 (2015).

32. Carter PR, Uppal H, Chandran S et al. Patients admitted to hospital with a diagnosis of atrial fibrillation outside of standard weekday working hours and at weekends have worse mortality and poorer survival. Eur. Heart J. 37, 303 (2016).

33. Potluri R. Is it time to re-appraise the weekend effect? J. R. Soc. Med. 108(10), 382-383 (2015).

34. Potluri R, Carter P, Kahn M et al. Heart failure patients discharged from hospital at weekends have worse mortality and poorer survival 14 year study from the United Kingdom from 2000-2013. Eur. Heart J. 37, 318 (2016). 
35. Hayes RM, Carter PR, Gollop ND et al. The impact of marital status on mortality and length of stay in patients admitted with acute coronary syndrome. Int. J. Cardiol. 212, 142-144 (2016).

36. Carter P, Uppal H, Chandran S et al. Marriage is associated with lower mortality rates in patients with acute coronary syndromes and modifiable cardiovascular risk factors. Eur. Heart J. 38, 504 (2017).

37. Rasoul D, Potluri S, Wong SC et al. Psychiatric comorbidities in patients with dilated cardiomyopathy. Int. J. Cardiol. 191, 71-73 (2015).

38. Yssennagger L, Gollop ND, Gorantla RS et al. Increasing burden of psychiatric comorbidities among patients with ischaemic heart disease. Int. J. Cardiol. 186, 200-201 (2015).

39. Teo R, Gollop ND, Baig M, Uppal H, Chandran S, Potluri R. The burden and trends of psychiatric co-morbidities among patients with cardiomyopathy. Int. J. Cardiol. 174(2), 398-399 (2014). 